\title{
Metas de Déficit: Transferências Intergovernamentais e o Controle do Endividamento dos Estados*
}

\author{
Henrique Augusto Alarcon Pires ${ }^{* *}$ \\ Maurício Soares Bugarin ${ }^{* * *}$
}

Sumário: 1. Introdução; 2. Fatos estilizados; 3. Modelos de metas de déficit fiscal; 4. Conclusão.

Palavras-chave: metas de déficit; contratos ótimos; desenho de mecanismos; disciplina de mercado; federalismo fiscal.

Códigos JEL: H77; H72; H63.

O plano de estabilização econômica de 1994 (Plano Real) foi marcado pela drástica redução dos índices de inflação no país, associada a um crescente descontrole fiscal dos estados e da União. Este artigo propõe um mecanismo de estímulo à disciplina fiscal por meio de um contrato ótimo de transferências entre o governo federal e os estados. Três situações são analisadas. Em primeiro lugar, mostrase que uma regra de transferências intergovernamentais ótima pode ser usada para reduzir consideravelmente os déficits subnacionais. Em seguida, prova-se que renegociações de dívidas estaduais sem regras de controle fixas tendem a gerar um comportamento ainda mais irresponsável dos entes subnacionais. Finalmente, mostra-se que mesmo quando não é possível implementar-se a regra ótima de transferência, a ocorrência de renegociação de dívidas pode ser usada de forma a se estabelecer um controle pelo menos parcial do processo de endividamento crescente dos estados.

This article studies the incentives for fiscal discipline faced by local governments (states) in a federalist system where revenue-sharing transfers are important sources of income for the states. Based on a market-discipline type of model of state-expenditure policy, it shows that the central government can use the transfers as a

\footnotetext{
*Artigo recebido em mai. 2001 e aprovado em set. 2002. Os autores agradecem a Mirta Bugarin, Marcelle Chauvet, Fábio Kanczuk, Flávio Versiani e a um parecerista anônimo, bem como aos participantes do V Encontro da Associação de Economia da América Latina e Caribe Lacea Rio 2000 - , pelos comentários a uma versão preliminar deste artigo. Uma versão anterior deste foi classificada em $1^{\circ}$ lugar na área de dívida pública no IV Prêmio Tesouro Nacional em Finanças Públicas, Brasília, 1999.

** Doutorando em economia pela Universidade de Brasília (UnB) e analista de finanças e controle do Ministério da Fazenda. E-mail: hpires@terra.com.br.

*** Departamento de Economia, UnB. E-mail: bugarin@unb.br.
} 
powerful mechanism to induce the states into choosing lower levels of fiscal deficits. This is accomplished by making the transfers contingent on an optimally chosen 'deficit targeting' rule, in such a way that the farther the state realized deficit from the targeted level, the lower the transfers from the central government. State debt-renegotiation process is shown to be a good opportunity for implementing such a rule by using an individually rational, incentive compatible contract between the states and the federal government.

\section{Introdução}

O plano de estabilização econômica implantado no Brasil em julho de 1994 e conhecido como Plano Real mostrou-se eficaz no controle da inflação, reduzindo-a de um patamar de 46,58\% ao mês em junho de 1994 a impressionantes $2,62 \%$ um ano depois. ${ }^{1}$ Ao controle da inflação, no entanto, está associado um aumento no descontrole fiscal. De fato, conforme dados do Banco Central, ${ }^{2}$ a dívida líquida do setor público elevou-se de $28,2 \%$ do PIB em julho de 1995 para $41,2 \%$ do PIB em fevereiro de 2001, um significativo aumento de $46 \%$. No caso dos governos estaduais, porém, o descontrole foi ainda mais pronunciado, passando a dívida líquida agregada desses entes da Federação de 8,1 para 15,6\% do PIB no mesmo período, um crescimento de $93 \%$.

Tais indicadores sugerem que o problema da dívida no Brasil tem sido mais presente no âmbito estadual do que no federal. Uma das possíveis explicações para essa realidade é a existência, até recentemente, de um mecanismo perverso de renegociação, pelo qual os estados conseguiam transferir partes significativas de suas dívidas com o setor privado para novas dívidas com o governo federal, em condições extremamente favoráveis para as unidades subnacionais e sem exigência prática de contrapartida de ajuste fiscal. ${ }^{3}$ Esse mecanismo pode ter gerado um incentivo adverso no comportamento dos entes da Federação no sentido de gastar muito na expectativa de que em algum momento o governo federal viria a socorrêlos.

Associado ao incentivo acima descrito, outros mecanismos estimularam o crescimento das dívidas subnacionais. A existência de bancos estaduais emprestando grande volume de recursos aos seus próprios governos, na espera de socorro do

\footnotetext{
${ }^{1}$ Segundo o IGP-DI (Ipeadata, disponível em: http://www.ipeadata.gov.br).

${ }^{2}$ Segundo a evolução da dívida líquida do setor público (disponível em: http://www.bcb.gov.br).

${ }^{3}$ Para uma descrição do histórico dos contratos assinados vide Santos (1999).
} 
Banco Central em caso de crise, foi outro mecanismo de acumulação de dívida estadual, cujos efeitos subótimos foram evidenciados em Werlang e Fraga Neto (1995).

Finalmente, merece ser sublinhado que o próprio esforço de ajuste fiscal do governo federal pode ter um efeito adverso nas contas estaduais por meio do flypaper effect (Oates, 1991), dada a legislação de transferências intergovernamentais existente no Brasil. De fato, à medida que o governo federal se esforça em aumentar sua arrecadação tributária com vistas à redução de seu déficit, também aumentam as transferências constitucionais obrigatórias aos estados e municípios. Assim, os estados recebem mais recursos sem correspondente aumento no esforço tributário próprio, o que pode estimulá-los a uma política fiscal menos responsável, conforme estudado em Werneck (1995).

Deve-se notar que um grande esforço tem sido feito no sentido de diminuir os incentivos à indisciplina fiscal dos estados. Com relação ao flypaper effect, o governo federal tem-se esforçado em fazer uso crescente de impostos que não são transferíveis aos estados, como a CPMF. No tocante aos bancos estaduais, por outro lado, após a implantação do Proes (Programa de Incentivo à Redução da Presença do Setor Público Estadual na Atividade Bancária), alguns bancos foram ou estão sendo extintos e/ou transformados em agências de fomento, enquanto outros foram privatizados ou passaram para o controle da União para posterior privatização. ${ }^{4}$ Finalmente a Lei Complementar $\mathrm{n}^{o} 101$, de 4 de maio de 2000, conhecida como Lei de Responsabilidade Fiscal, constitui um grande marco nesse esforço de controle dos déficits públicos subnacionais. Essa lei proíbe a renegociação de dívidas e estabelece limites severos de endividamento aos estados, prevendo, inclusive, o encarceramento do governador que não respeitar esses limites.

Este artigo visa contribuir com o esforço de controle dos déficits públicos subnacionais, propondo um mecanismo alternativo que pode induzir os governos locais a reduzir suas dívidas. O instrumental analítico utilizado é a teoria de desenhos de mecanismos, ${ }^{5}$ que tem sido aplicada com sucesso ao controle da política mo-

\footnotetext{
${ }^{4}$ De um total de 25 bancos estaduais existentes em 1995, seis foram privatizados (Banespa, Banerj, Baneb, Bemge, Bandepe, Banestado), seis foram federalizados (BEA, BEC, BEG, BEM, BEP, Besc), seis estão em processo de liquidação (Banacre, Produban, Banap, Bemat, Bandern, Beron) e um foi extinto (Baner); ainda há quatro bancos saneados (Banestes, Banrisul, Banese, Banpara), sendo os dois restantes o BRB e o Paraiban; estes seis últimos permanecem sob o controle dos estados. Fonte: Secretaria do Tesouro Nacional.

${ }^{5}$ Os autores desconhecem a existência de consenso sobre a forma correta da tradução para o português da expressão "mechanism design", tendo um parecerista anônimo sugerido a expressão alternativa "projeto de mecanismos". Os autores optaram por manter a denominação "desenho de mecanismos", ressaltando que se trata de uma tradução livre e assumindo inteira responsabilidade pelo seu uso.
} 
netária (Walsh, 1995, Svensson, 1997). O artigo desenvolve, no âmbito da política fiscal, modelos semelhantes àqueles usados na literatura de política monetária. Nesses modelos principal-agente, o governo central, no seu papel de regulador do federalismo (Oates, 1991) é o principal, que deseja projetar regras ótimas de transferência de recursos aos governos subnacionais, de forma a induzir, nesses entes da Federação, uma política responsável de gastos públicos. Os estados, por sua vez, são os agentes que, dados os incentivos formulados pelo governo federal, decidem quanto gastar.

O principal resultado do artigo é que o governo federal pode usar as regras de transferências intergovernamentais como um importante instrumento de correção do "viés deficitário" observado na condução das políticas fiscais dos governos subnacionais.

O artigo está estruturado em quatro seções. A seção 2 apresenta um estudo econométrico preliminar que sugere, por um lado, um comportamento estacionário da série temporal das receitas agregadas dos governos estaduais e, por outro lado, um comportamento não-estacionário da série temporal das dívidas agregadas dos mesmos estados. Esses fatos estilizados confirmam a urgência de se desenvolver um mecanismo de controle dos déficits dos governos subnacionais.

A seção 3 apresenta a principal contribuição do artigo. O ponto de partida é o modelo de maximização de gastos dos estados de Werneck (1995), descrito na seção 3.1. Em seguida, utilizam-se um modelo principal-agente e a estrutura dos modelos de metas inflacionárias para desenvolver diferentes mecanismos que poderão ser usados pelo governo federal a fim de induzir os governos locais a restringir seus déficits. A seção 3.2 mostra que quando a União pode impor aos estados uma regra de transferência de recursos condicionada a critérios de desempenho fiscal, um contrato ótimo pode restringir consideravelmente os déficits estaduais. A seção 3.3 mostra o resultado adverso de renegociações das dívidas estaduais quando não há mecanismo de controle por parte da União. Finalmente, a seção 3.4 mostra que mesmo quando a União não pode impor aos estados a regra de transferências estudada em 3.2, o governo federal possui, na renegociação da dívida dos estados, um instrumento importante de controle dos déficits subnacionais. Nessa situação, a restrição de racionalidade individual dos estados limita a capacidade de controle do governo federal; no entanto, as vantagens para os estados envolvidas numa renegociação de suas dívidas ainda permitem à União induzir um menor gasto dos governos subnacionais.

A seção 4 apresenta as considerações finais do artigo. 


\section{Fatos Estilizados}

Esta seção mostra os resultados econométricos sobre as séries da receita e dívida dos estados como motivadores para os modelos propostos na seção 3.

A questão do endividamento crescente do setor público foi estudada por Trehan e Walsh (1991) para os EUA e por Pastore (1995) e Issler e Lima (1999) para o Brasil. Os primeiros mostraram, por meio de simulação econométrica, que a restrição orçamentária intertemporal requer que a série da dívida seja estacionária. Issler e Lima (1999) e Pastore (1995) aplicam para o Brasil, no âmbito do governo federal, metodologias semelhantes à de Trehan e Walsh (1991), concluindo que a senhoriagem, ou seja, o imposto inflacionário, foi usada para garantir o equilíbrio do orçamento de longo prazo. Os resultados apresentados a seguir sugerem, no entanto, um comportamento distinto no âmbito dos governos estaduais quando se considera o período pós-Plano Real.

\subsection{Análise da série das receitas de ICMS dos estados brasileiros}

Esta seção descreve os resultados obtidos pela análise econométrica do comportamento das receitas do imposto sobre circulação de mercadorias e serviços (ICMS) e do fundo de participação dos estados (FPE).

As séries das receitas foram obtidas junto às secretarias de Fazenda dos estados e o FPE junto à Secretaria do Tesouro Nacional do Ministério da Fazenda (STN). Esses dados foram agregados para apurar-se a arrecadação total de ICMS e FPE dos estados, tomando-se esta como proxy para as receitas, visto que o ICMS é o tributo de maior peso nas arrecadações estaduais e o FPE representa a maior parte das receitas de transferências. Os valores estão em percentuais do PIB, cuja série foi obtida junto ao Ipea. Os dados encontram-se representados na figura 1.

A figura 1 sugere um comportamento estacionário da série. Para testar essa indicação foi realizado o teste $\mathrm{ADF}$ de raízes unitárias, cujos resultados são apresentados na tabela 1 . 
Figura 1

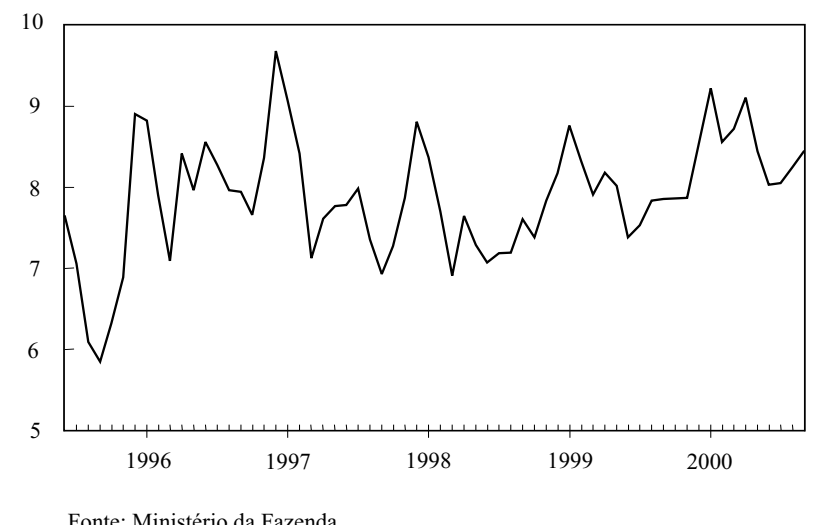

Tabela 1

Estatística ADF para a dívida agregada dos estados

\begin{tabular}{llll}
\hline Estatística ADF & $-4,17157$ & Valor crítico a $1 \%$ & $-3,5398$ \\
& & Valor crítico a $5 \%$ & $-2,9092$ \\
& Valor crítico a $10 \%$ & $-2,5919$ \\
\hline
\end{tabular}

A escolha do número de defasagens do teste (lag 2) obedeceu à metodologia descrita por Enders (1995, cap. 4). A série das receitas totais de ICMS e FPE no Brasil mostrou-se estacionária em nível, rejeitando a hipótese $H_{0}$ de existência de raiz unitária a um nível de significância de 1\%. Esse resultado sugere que nos cinco anos correspondentes ao período analisado (de 1995 a 2000) não houve crescimento significativo da arrecadação, após a elevação de receita observada com o fim da inflação e do efeito Tanzi no início do Plano Real.

\subsection{Análise da série das dívidas dos estados}

Confirmado o caráter estacionário das receitas estaduais, uma questão que se coloca refere-se ao comportamento das dívidas estaduais. No período analisado após o Plano Real, com a redução das receitas financeiras por meio do imposto inflacionário, todos os estados aumentaram suas dívidas devido à acumulação de déficits sucessivos (Santos, 1999).

A figura 2 mostra a dívida consolidada dos estados brasileiros, a partir de dados do Banco Central, em relação ao PIB no mesmo período considerado no estudo 
sobre a arrecadação. A figura apresenta indicações de crescimento explosivo das dívidas dos estados após o Plano Real.

Figura 2

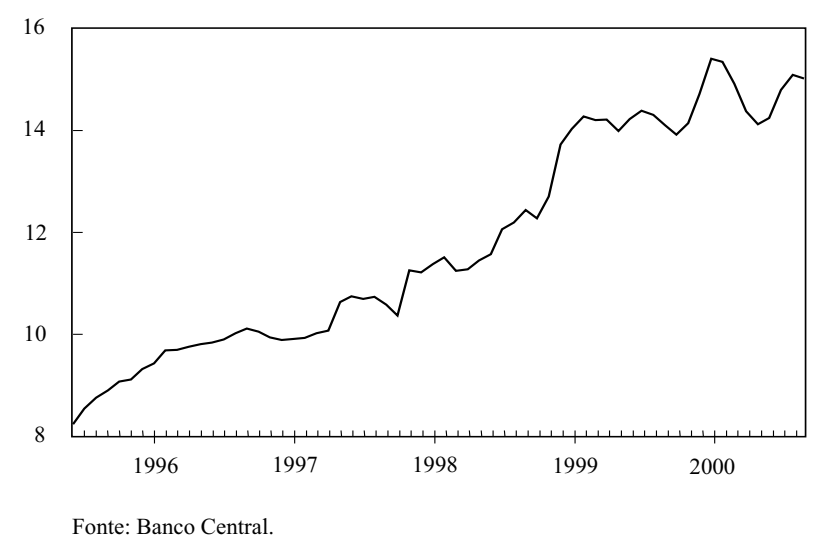

Para testar essas indicações, assim como no caso da arrecadação de ICMS, foi realizado o teste $\mathrm{ADF}$ de raízes unitárias. Os resultados do teste para a série da dívida dos estados encontram-se na tabela 2 .

\section{Tabela 2}

Estatística ADF para a despesa agregada dos estados

\begin{tabular}{llll}
\hline Estatística ADF & $-0,53076$ & Valor crítico a $1 \%$ & $-3,5267$ \\
& & Valor crítico a $5 \%$ & $-2,9035$ \\
& Valor crítico a $10 \%$ & $-2,5859$ \\
\hline
\end{tabular}

A escolha do número de defasagens do teste (lag 3) obedeceu, novamente, à metodologia descrita em Enders (1995). Os resultados mostram que, para qualquer nível de significância, não foi rejeitada a hipótese nula $H_{0}$ da não-estacionariedade da série, sugerindo, assim, que a série das dívidas dos estados possui raiz unitária.

\subsection{Conclusão do estudo econométrico}

Os resultados econométricos sugerem que no âmbito dos governos estaduais há um insustentável desequilíbrio entre o comportamento da dívida pública e o crescimento de suas receitas estaduais no período pós-Plano Real. Diferentemente dos estudos de Pastore (1995), que mostram que o endividamento do governo 
federal é sustentável no longo prazo, e do trabalho de Issler e Lima (1999), que não rejeita a hipótese de estacionariedade do déficit público federal, para a questão do déficit público no âmbito estadual os testes apresentam indicações de um caráter explosivo da série da dívida em contraposição a um caráter limitado da série das receitas, no período pós-Plano Real.

As tendências apontadas pelo estudo econométrico confirmam a necessidade de se desenvolver mecanismos de controle dos déficits estaduais, o que constitui o principal objetivo deste artigo.

\section{Modelos de Metas de Déficit Fiscal}

\subsection{O modelo de Werneck sem regra de controle}

Esta seção apresenta o modelo formalizado por Werneck (1995), com pequenas modificações. As preferências de cada estado $E$ são descritas por uma função de bem-estar social $U$ diferenciável, estritamente crescente e estritamente côncava em seu nível de gastos $G_{E}$ :

$$
U=U\left(G_{E}\right)
$$

O nível de gastos de $E$ satisfaz a restrição orçamentária:

$$
G_{E}=D_{E}-r_{E} B_{E}+T_{E}
$$

em que $D_{E}$ é o déficit fiscal, $B_{E}$ o estoque da dívida, $r_{E}$ a taxa de juros paga sobre o estoque da dívida e $T_{E}$ a receita total, sendo todas as variáveis referentes ao estado $E$.

A receita total do estado é composta por uma parcela de arrecadação tributária própria do estado, principalmente o ICMS (imposto sobre circulação de mercadorias e serviços), e por uma parcela de transferências constitucionais recebidas da União Federal, que corresponde à parcela do FPE (fundo de participação dos estados), à qual cada unidade federativa tem direito. Assim, pode-se escrever:

$$
T_{E}=T_{P E}+\delta T_{U}
$$

em que $T_{P E}$ é a arrecadação própria e $\delta$ é o percentual das receitas totais da União, $T_{U}$, transferidas ao estado.

O outro componente de (2), $r_{E} B_{E}$, é definido como os juros pagos pelo estado sobre sua dívida, onde $r_{E}$ é equivalente à taxa de juros $r_{U}$ paga pela União sobre sua própria dívida $B_{U}$, mais uma taxa de juros (spread) que é função crescente do 
déficit do estado e decrescente da relação receita/dívida do estado. Esta hipótese é motivada pelo fato de antes do refinanciamento o estado pagar uma taxa de juros superior àquela paga pela União em seus títulos públicos. Desta forma, tem-se:

$$
r_{E}=r_{U}+r\left(D_{E}, \frac{T_{E}}{B_{E}}\right) \operatorname{com} \frac{\partial r}{\partial D_{E}}>0 ; \frac{\partial r}{\partial \frac{T_{E}}{B_{E}}}<0
$$

Substituindo (3) em (4) obtém-se: ${ }^{6}$

$$
r_{E}=r_{U}+r\left[D_{E}, \frac{T_{P E}+\delta T_{U}}{B_{E}}\right]
$$

Assim, a restrição orçamentária do governo estadual pode ser reescrita como:

$$
G_{E}=D_{E}-B_{E} r_{U}-r\left(D_{E}, \frac{T_{P E}+\delta T_{U}}{B_{E}}\right) B_{E}+T_{P E}+\delta T_{U}
$$

Destarte, o problema de maximização do estado pode ser escrito como:

$$
\begin{gathered}
\operatorname{Max}_{D_{E}} U=U\left(G_{E}\right) \\
\text { s.a: } G_{E}=D_{E}-r_{E} B_{E}+T_{P E}+\delta T_{U} \\
r_{E}=r_{U}+r\left[D_{E}, \frac{T_{P E}+\delta T_{U}}{B_{E}}\right]
\end{gathered}
$$

Substituindo (5) e (3) em (2), o problema se reduz a:

$$
\underset{D_{E}}{\operatorname{Max}} U\left(D_{E}-B_{E} r_{U}-r\left(D_{E}, \frac{T_{P E}+\delta T_{U}}{B_{E}}\right) B_{E}+T_{P E}+\delta T_{U}\right)
$$

Resolvendo para $D_{E}$, obtém-se a seguinte condição de primeira ordem (CPO):

$$
U^{\prime}\left(G_{E}\right)\left(1-\frac{\partial r}{\partial D_{E}}\left(D_{E}, \frac{T_{P E}+\delta T_{U}}{B_{E}}\right) B_{E}\right)=0
$$

que equivale a:

\footnotetext{
${ }^{6} \mathrm{~A}$ taxa de juros paga pela União é função também do déficit da União $D_{U}$ e da relação receita/dívida da União $r_{U}=r\left(D_{U}, T_{U} / B_{U}\right)$. No entanto, este modelo não considera o efeito das decisões do estado sobre $D_{U}$ ou $T_{U} / B_{U}$ e, portanto $r_{U}$ é suposta constante.
} 


$$
\frac{\partial r}{\partial D_{E}}\left(D_{E}, \frac{T_{P E}+\delta T_{U}}{B_{E}}\right) B_{E}=1
$$

Assim a condição (8) determina o nível de déficit do governo do estado, denotado por $D_{E}^{N}$, que maximiza suas despesas $G_{E}$, ou seja, sua decisão de endividamento. O lado esquerdo representa o custo adicional com o aumento de uma unidade do déficit $D_{E}$, isto é, o custo extra com pagamento do serviço da dívida sobre o estoque $B_{E}$ devido ao aumento dos juros $r_{E}$. O lado direito representa o ganho adicional com o aumento de uma unidade da dívida. Destarte, enquanto o custo marginal,

$$
\frac{\partial r}{\partial D_{E}}\left(D_{E}, \frac{T_{P E}+\delta T_{U}}{B_{E}}\right) B_{E}
$$

for menor que o ganho marginal, 1, o estado terá incentivo a aumentar sua dívida.

Exemplo - Para ilustrar a decisão do estado, considere a seguinte parametrização da função taxa de juros $r$ :

$$
r\left(D, \frac{T}{B}\right)=a+b D^{2}-c \frac{T}{D}
$$

em que $a, b, c>0$. Então,a função $r$ satisfaz as hipóteses do modelo e a condição de primeira ordem é dada por:

$$
D_{E}^{N}=\frac{1}{2 b B_{E}}
$$

Assim, quanto maior for o estoque da dívida estadual, menor será seu déficit atual. Além disso, quanto mais sensível for o mercado ao déficit estadual, maior será $b$ e, portanto, menor será o déficit escolhido pelo governo estadual.

É importante observar que no presente modelo o mercado alinha os incentivos por intermédio da taxa de juros, que aumenta à medida que o estado expande seu déficit. Em particular, não se considera a possibilidade de uma moratória estadual ou de transferência da dívida estadual para a União. ${ }^{7}$ Pode-se argumentar, naturalmente, que o risco de uma moratória estadual já se encontra embutido no formato da função $r$; no entanto, é importante esclarecer que, por ser essencialmente estático, este modelo não é suficientemente abrangente para considerar

\footnotetext{
${ }^{7}$ Os autores agradecem a um revisor anônimo por este comentário.
} 
questões dinâmicas mais profundas, como a moratória estadual. ${ }^{8}$ Por outro lado, a questão da transferência da dívida estadual para a União é tratada nas seções 3.3 e 3.4 .

A próxima seção apresenta um modelo de controle que tem por objetivo induzir o estado a optar por menores níveis de déficit.

\subsection{Transferência com regra de controle: uma análise de second best}

No modelo descrito em 3.1 a União transfere para o estado um percentual fixo de sua arrecadação, $\delta T_{U}$, independentemente da política fiscal do estado. Trata-se de uma restrição constitucional que pode ter um efeito adverso no controle dos gastos estaduais. Conforme observou Werneck (1995), um aumento na arrecadação da União implica um aumento do repasse aos estados, que, por sua vez, têm renovado incentivo à manutenção dos déficits.

Por outro lado, o repasse aos estados por meio do FPE constitui o melhor instrumento que a União possui para discipliná-los, desde que esse repasse seja condicionado a certos critérios de controle fiscal.

Esta seção inclui, no modelo original, a possibilidade de um tal mecanismo, fazendo $\delta$ uma função de $D_{E}-D_{E^{*}}$, em que $D_{E}$ é o nível de déficit realizado do estado e $D_{E^{*}}$ corresponde ao nível ótimo para a União, podendo ser até mesmo $D_{E^{*}}=0$ ou negativo, correspondendo a um superávit fiscal. O modelo postula que o nível ótimo de endividamento é menor que aquele escolhido pelo estado quando não existem restrições outras que o mercado:

$$
D_{E}^{*}<D_{E}^{N}
$$

Essa hipótese tem sua justificativa nos fatos estilizados evidenciados na seção 2: o caráter explosivo das dívidas dos estados sugere que o equilíbrio de mercado resulta num nível de déficit demasiadamente elevado. Alternativamente, a Lei de Responsabilidade Fiscal sugere que a União tem por objetivo, de fato, reduzir o déficit dos estados.

Toma-se, então, $\delta=f\left(D_{E}-D_{E^{*}}\right)$, em que $f$ é uma função continuamente diferenciável $\left(C^{1}\right)$, de pico único, atingindo seu máximo em $D_{E}=D_{E^{*}}$. Assim,

$$
\delta T_{U}=f\left(D_{E}-D_{E^{*}}\right) T_{U}
$$

\footnotetext{
${ }^{8}$ Para um tratamento dinâmico do problema da dívida estadual vide, por exemplo, Pires e Bugarin (2001). 
Nesse caso, o problema de maximização do estado é:

$$
\begin{gathered}
\operatorname{Max}_{D_{E}} U=U\left(G_{E}\right) \\
\text { s.a }: G_{E}=D_{E}-r_{U} B_{E}-r\left(D_{E}, \frac{T_{P E}+f\left(D_{E}-D_{E}^{*}\right) T_{U}}{B_{E}}\right) B_{E} \\
+T_{P E}+f\left(D_{E}-D_{E}^{*}\right) T_{U}
\end{gathered}
$$

A nova CPO será:

$$
\begin{gathered}
U^{\prime}\left(G_{E}\right) \quad\left[1-\left(\frac{\sigma r}{\delta D_{E}}\left(D_{E}, \frac{T_{E}}{B_{E}}\right)+\frac{\delta r}{\delta \frac{T_{E}}{B_{E}}}\left(D_{E}, \frac{T_{E}}{B_{E}}\right) \frac{f^{\prime}\left(D E-D_{e}^{*}\right)}{B_{E}} T_{U}\right) B_{E}\right. \\
\left.+f^{\prime}\left(D_{E}-D_{E}^{*}\right) T_{U}\right]=0
\end{gathered}
$$

o que equivale a:

$$
\frac{\partial r}{\partial D_{E}}\left(D_{E}, \frac{T_{P E}+f\left(D_{E}-D_{E}^{*}\right) T_{U}}{B_{E}}\right) B_{E}=1-\alpha
$$

em que:

$$
\alpha=\left[-f^{\prime}\left(D_{E}-D_{E}^{*}\right) T_{U}\right]\left[1-\frac{\sigma r}{\sigma \frac{T_{E}}{B_{E}}}\left(D_{E}, \frac{\left.T_{P E}+f\left(D_{E}-D_{E}^{*}\right) T_{U}\right)}{B_{E}}\right)\right]>0
$$

Assim a condição (10) determina o nível de déficit do governo do estado que maximiza suas despesas $G_{E}$, ou seja, sua decisão de endividamento, porém, agora, com a introdução da regra de controle prevista em (9). O lado esquerdo tem a mesma interpretação que na seção 3.1. Em contrapartida, a introdução da regra de controle $f$ torna o lado direito menor do que 1 (para valores de $D_{E}$ maiores que $D_{E^{*}}$ ), de forma que a nova solução do problema do estado envolve a escolha de um déficit menor que no caso apresentado na seção 3.1.

Exemplo - Para ilustrar o efeito de se condicionar as transferências intergovernamentais ao desempenho fiscal de um estado, considere a função de juros $r$ parametrizada no exemplo anterior e suponha que a União deseje estabelecer otimamente uma regra de transferência do tipo $f\left(D-D^{*}\right)=\gamma-k\left(D-D^{*}\right)$, em 
que $k$ é um parâmetro a ser determinado, de forma a induzir um nível de déficit $D^{*}$. Então, a nova condição de primeira ordem é:

$$
D=\frac{1-k(1-c) T_{U}}{2 b B_{E}}
$$

Logo, para induzir o nível de déficit $D^{*}$, basta a União selecionar o seguinte valor de $k$ :

$$
k=\frac{1-2 b D^{*} B_{E}}{(1+c) T_{U}}
$$

Observe que, como $D_{E}^{*}<D_{E}^{N}$, tem-se $k \in(0,1)$ desde que $T_{U}>1$.

A solução encontrada no exemplo permitiu a obtenção do nível exato de déficit desejado pela União. Trata-se, no entanto, de um caso particular; em geral o nível de controle da União sobre os gastos do estado depende do formato específico da função $r$, assim como dos valores das demais variáveis do modelo.

Voltando ao problema mais geral, deve-se observar que, quanto maior for o valor absoluto de $f^{\prime}$, maior será $\alpha$ e, conseqüentemente, menor será $1-\alpha$. Assim, escolhendo $f$ de forma apropriada $\left(\left|f^{\prime}\right|\right.$ suficientemente grande), a União pode induzir o estado a escolher níveis de déficit mais próximos de $D_{E^{*}}$, o nível ótimo para o governo federal. Todavia, não se pode garantir, em geral, que o estado escolherá $D_{E}=D_{E^{*}}$, o que seria o first best do ponto de vista do governo federal. Logo, a introdução de uma regra de controle pode ser vista como um mecanismo que induz déficits menores, mas não necessariamente o nível ótimo de déficit $D_{E^{*}}$. Trata-se, pois, de um equilíbrio do tipo second best.

A forma legal para a aplicação desse contrato, no entanto, requer uma emenda constitucional, uma vez que a Constituição de 1988 exclui a possibilidade de restringir os repasses do FPE aos estados. Por outro lado, a negociação no Congresso Nacional de uma tal emenda apresenta-se extremamente complexa. Assim, as dificuldades políticas de implementação de um sistema de metas de déficits poderiam inviabilizar a proposta que, do ponto de vista técnico, é relativamente simples.

A despeito dos naturais entraves políticos, deve-se observar que por ocasião último programa de renegociação das dívidas estaduais, em que o governo federal assumiu as dívidas dos estados, uma das cláusulas contratuais previa a retenção do FPE para o estado que não cumprisse as metas de ajuste fiscal, tendo o bloqueio sido aplicado com o governo de Minas Gerais. ${ }^{9}$ Essa cláusula, de fato, aproxima-se

\footnotetext{
${ }^{9}$ Em janeiro de 1999, devido à inadimplência (ou seja, o não-pagamento da parcela de refinanciamento) do estado de Minas Gerais, foram executadas as garantias contratuais de retenção
} 
da proposta do presente modelo.

A próxima seção evidencia a magnitude do viés deficitário oriundo de um processo de renegociação de dívidas sem contrapartida de controle.

\subsection{Renegociação sem regra de controle}

Esta seção estuda uma situação na qual a União renegocia a dívida de um estado sem exigir nenhuma contrapartida em termos do controle do déficit. Nesse caso, a renegociação consiste simplesmente no repasse da dívida do estado para a União, sendo o estado obrigado a pagar a dívida à União sujeito às taxas de juros menores, ${ }^{10} r_{U}$.

Assim, o novo problema do estado passa a ser:

$$
\begin{gathered}
\operatorname{Max}_{D_{E}} U\left(G_{E}\right) \\
\text { s.a: } G_{E}=D_{E}-r_{U} B_{E}+T_{P E}+\delta T_{U}
\end{gathered}
$$

Observe que o problema de maximização acima não possui solução, uma vez que o estado tem um incentivo para acumular um déficit infinito. Dois fenômenos explicam esse resultado. Por um, lado o déficit $D_{E}$ não se reflete negativamente na taxa de juros paga pelo estado, uma vez que o estoque da dívida está sujeito à taxa fixa $r_{U}$. Por outro lado, o déficit $D_{E}$ tampouco se reflete nas transferências da União, que também são fixas, dadas pelo coeficiente $\delta$. Ambos os fenômenos estimulam o estado a aumentar sua dívida muito acima do que ocorreria caso não houvesse renegociação com a União. ${ }^{11}$

Em suma, é melhor para a União não assinar nenhum contrato com o estado do que assumir a dívida do estado sem nenhuma contrapartida, ${ }^{12}$ uma vez que o estado, diante de juros mais baixos, tem um incentivo ainda maior a gastar. Trata-se, pois, da pior situação possível para a União.

da cota-parte do FPE do estado junto ao Tesouro Nacional.

${ }^{10}$ De fato, é comum nos processos de renegociação que os estados obtenham uma taxa de juros subsidiada inferior à taxa paga pela União, $r_{U}$. Vide, a esse respeito, Santos (1999).

${ }^{11} \mathrm{O}$ único elemento de controle do déficit são os juros que aparecerão nos períodos futuros, sobre o novo estoque da dívida, uma vez que esse novo estoque não foi incluído no contrato de renegociação e, portanto, deverá ser pago às taxas de juros mais elevadas associadas ao estado. No entanto, o modelo atual, essencialmente estático, não engloba este tipo de análise.

${ }^{12}$ Como tem sido o caso das renegociações ocorridas anteriormente ao Programa de Reestruturação e Ajuste Fiscal dos estados de 1997. Vide Pires (1999) e Santos (1999) 


\subsection{Renegociação sem discricionariedade: uma análise de third best}

Como foi visto em 3.2, a União consegue controlar melhor os déficits dos estados se tiver a possibilidade de condicionar as transferências à relação $D_{E}-D_{E^{*}}$, ou seja, a relação entre o déficit desejado $D_{E^{*}}$ e o déficit realizado $D_{E}$. A dificuldade política de se implementar uma regra dessa natureza, podendo inclusive exigir uma reforma constitucional, sugere o estudo de um modelo intermediário, em que é dado ao estado a opção de não assinar nenhum contrato de renegociação, garantindo a transferência constitucional $\delta T_{U}$, mas enfrentando os juros $r_{E}$, ou de renegociar sua dívida com base nos juros menores $r_{U}$, mas aceitando a nova regra de transferência $f\left(D_{E}-D_{E^{*}}\right) T_{U}$.

Caso o estado não renegocie sua dívida, a restrição orçamentária será:

$$
G_{E}=D_{E}-r_{U} B_{E}-r\left(D_{E}, \frac{T_{P E}+\delta T_{U}}{B_{E}}\right) B_{E}+T_{E}
$$

A solução desse problema $\left(D_{E}^{N}\right)$, estudada em 3.1 e em Werneck (1995), satisfaz à equação:

$$
\frac{\partial r}{\partial D_{E}}\left(D_{E}^{N}, \frac{T_{P E}+\delta T_{U}}{B_{E}}\right) B_{E}=1
$$

Assim o gasto $G_{E}^{N}$ que maximiza a utilidade do estado nesse caso é dado por:

$$
G_{E}^{N}=D_{E}^{N}-r_{U} B_{E}-r\left(D_{E}^{N}, \frac{T_{P E}+\delta T_{U}}{B_{E}}\right) B_{E}+T_{P E}+\delta T_{U}
$$

Por outro lado, sejam $D_{E}^{C}$ e $G_{E}^{C}$ os respectivos déficit e gasto escolhidos pelo estado quando assina o contrato com a União. Então, $D_{E}^{C}$ e $G_{E}^{C}$ satisfazem:

$$
G_{E}^{C}=D_{E}^{C}-r_{U} B_{E}+T_{P E}+f\left(D_{E}^{C}-D_{E}^{*}\right) T_{U}
$$

É interessante comparar a expressão acima com a equação (5). Em (5) o governo estadual arca com todo o custo do estoque de sua dívida na forma de juros mais elevados, $r_{E}=r_{U}+r$, mas tem garantida a transferência $\delta T_{U}$. Por outro lado, em (12) o estado tem acesso a uma taxa de juros mais reduzida, $r_{U}$, mas suas transferências são agora função de seu desempenho fiscal: $f\left(D_{E}^{C}-D_{E}^{*}\right) T_{U}$.

Assim, o contrato ótimo a ser proposto pela União, ou seja, aquele que minimiza o déficit do estado, é a solução do seguinte problema do governo federal: 


$$
\begin{gathered}
\min _{f, D_{E}^{C}}\left(D_{E}^{C}-D_{E}^{*}\right)^{2} \\
\text { s.a }: G_{E}^{C} \geq G_{E}^{N} \\
D_{E}^{C} \in \arg \max \left\{D_{E}^{C}-r_{U} B_{E}+T_{P E}+f\left(D_{E}^{C}-D_{E}^{*}\right) T\right\}
\end{gathered}
$$

A restrição de racionalidade individual ou restrição de participação (13) exige que o estado não perca utilidade se assinar o contrato com a União. Observe que o termo $G_{E}^{N}$ na expressão acima é obtido resolvendo-se o problema em 3.1. A condição (14), que poderia ser chamada de condição de compatibilidade de incentivos, reconhece que o governo, uma vez assinado o contrato de renegociação da dívida, escolherá sua nova dívida de forma a maximizar sua utilidade, levando em consideração o esquema de incentivos introduzido pela nova regra de transferência.

Como a União deseja induzir um déficit mínimo, escolherá $f$ de forma que toda a renda adicional que o estado $E$ recebe (ao deixar de pagar juros elevados ao aceitar o contrato) seja usada na redução de seu déficit, mantendo o gasto $G_{E}^{C}$ em seu valor mínimo possível, isto é, $G_{E}^{C}=G_{E}^{N}$. Isto é obtido penalizandose fortemente o estado $E$ por meio de uma menor transferência $f\left(D_{E}^{C}-D_{E}^{*}\right) T_{U}$, quando o valor de $D_{E}^{C}$ escolhido for muito maior que $D_{E}^{*}$. De fato, a condição de otimalidade $G_{E}^{C}=G_{E}^{N}$ pode ser reescrita, igualando-se (11) a (12), como:

$$
D_{E}^{N}-D_{E}^{C}=r\left(D_{E}^{N}, \frac{T_{P E}+\delta T_{U}}{B_{E}}\right) B_{E}-\left(\delta-f\left(D_{E}^{C}-D_{E}^{*}\right)\right) T_{U}
$$

A expressão (15) fornece o ganho máximo possível para a União em termos da redução no déficit do estado $D_{E}^{N}-D_{E}^{C}$ em um ambiente institucional no qual o estado pode optar se renegocia sua dívida ou não. O primeiro termo à direita, $r\left(D_{E}^{N}, \frac{T_{P E}+\delta T_{U}}{B_{E}}\right) B_{E}$, corresponde à economia que o estado faz ao pagar o estoque de sua dívida a juros reduzidos; o segundo termo, $\left(\delta-f\left(D_{E}^{C}-D_{E}^{*}\right)\right) T_{U}$, corresponde à redução das transferências da União quando o contrato é assinado. $\mathrm{O}$ termo à esquerda mostra que num contrato ótimo todo o ganho líquido do estado com o novo contrato é direcionado para a redução de seu déficit.

Em suma, a restrição de participação (13) pode reduzir a capacidade de controle da União, uma vez que ela é obrigada a garantir ao estado $E$ um gasto mínimo $G_{E}^{N}$, para que este aceite renegociar sua dívida. ${ }^{13}$ No entanto, o governo

\footnotetext{
${ }^{13}$ No caso second best estudado em 3.2 esta limitação não existia, permitindo assim um maior controle da União.
} 
federal ainda mantém certo controle, que é capaz de induzir $E$ a usar a totalidade da renda líquida proveniente do contrato na redução do seu déficit. Trata-se, pois, de um mecanismo do tipo third best.

Exemplo - Para ilustrar o problema da União quanto à renegociação considere a parametrização usada anteriormente para as funções $r$ e $f$. Dado o parâmetro $k$, a solução do problema do estado após renegociação da dívida é dada por: $D_{E}^{C}=\frac{1-k(1-c) T_{U}}{2 b B_{E}}$. Conforme visto, para induzir um nível de déficit $D_{E}^{*}$ basta a União escolher o valor $k=\frac{1-2 b D_{E}^{*} B_{E}}{(1+c) T_{U}}$. Trata-se da solução da restrição (14). Nesse caso, se o estado aceitar o contrato de renegociação e escolher otimamente seu nível de déficit, o gasto total do estado será:

$$
G_{E}^{C}=D_{E}^{*}-r_{U} B_{E}+T_{P E}+\delta T_{U}
$$

Por outro, se decidir não aceitar a proposta de renegociação do governo, o gasto total do estado será:

$$
G_{E}^{N}=\frac{1}{2} \frac{1}{B_{E}}\left(\frac{1}{b}-\frac{1}{2}\right)-\left(a+r_{U}\right) B_{E}+(1-c)\left(T_{P E}+\delta T_{U}\right)
$$

Usando agora a restrição de participação (13), conclui-se que o menor gasto que a União consegue impor ao estado por meio desse contrato é:

$$
\bar{D}_{E}=\frac{1}{2 b B_{E}}-\frac{1}{4 B_{E}}-c\left(T_{P E}+\delta T_{U}\right)
$$

Observe que o resultado com renegociação é melhor que aquele sem renegociação, que é dado por $D_{E}^{N}=\frac{1}{2 b B_{E}}$; assim, a União consegue reduzir o déficit dos estados, mesmo diante das restrições (13) e (14), que têm de ser satisfeitas para que o estado aceite assinar o contrato de renegociação. No entanto, para o formato usado da função de transferência $f$, a expressão (16) mostra que existe um limite inferior para a redução de déficit que pode ser induzida por meio dos contratos de renegociação:

$$
D_{E}^{*} \geq \bar{D}_{E}=\frac{1}{2 b B_{E}}-\frac{1}{4 B_{E}}-c\left(T_{P E}+\delta T_{U}\right)
$$

\section{Conclusão}

Este artigo tentou analisar os incentivos para a disciplina fiscal com os quais se defrontam os estados num sistema federalista no qual transferências intergover- 
namentais desempenham um papel importante na decisão de gastos desses entes federados.

Um estudo econométrico preliminar mostrou que, enquanto as séries temporais das receitas agregadas dos estados apresentam um comportamento estacionário, as séries temporais de suas dívidas agregadas apresentam um comportamento explosivo. Estes fatos estilizados, aliados ao histórico do comportamento entre a União e os estados, marcado pela ausência de cláusulas fortes de controle do déficit após a renegociação, sugerem um viés deficitário na política fiscal dos governos subnacionais e servem de motivação para a construção de um modelo para reduzir os gastos subnacionais.

A partir de um modelo básico de Werneck (1995) de maximização de gastos dos estados, foi construída uma regra ótima de transferência de recursos da União que introduz um mecanismo de controle do endividamento dos estados pelo governo federal. O contrato resultante gera uma solução superior ao modelo original sem controle, isto é, um nível reduzido de déficit dos estados. Em seguida, foram analisados os efeitos adversos de uma renegociação das dívidas dos estados quando nenhum controle da União é imposto.

Finalmente, foi estudada uma situação possivelmente mais próxima às condições atuais de renegociação de dívidas, na qual a União não pode impor aos estados uma alteração nas transferências (constitucionais) sem que estes estados aprovem essa alteração. O estudo mostrou que um controle da União ainda é possível. Esse controle é reduzido pelas restrições institucionais, gerando um equilíbrio do tipo third best, mas o novo equilíbrio obtido é ainda superior à situação de renegociação sem controle.

A análise desenvolvida neste artigo pode ser estendida em várias direções. Em primeiro lugar, nota-se que o modelo prevê que, após a renegociação da dívida dos estados, estes têm acesso a uma taxa de juros sobre o estoque de suas dívidas que é idêntica à taxa de juros de mercado paga pela União. No entanto, o histórico de renegociação das dívidas mostra que essa taxa tende a ser ainda menor que $r_{U}$. Essa característica política do processo de renegociação sugere uma posição ainda mais forte da União, permitindo-lhe exigir metas de déficit ainda mais ousadas para assinar contratos com os estados.

Uma segunda extensão natural deste modelo consiste na análise dinâmica dos efeitos de uma renegociação. O que ocorrerá se o descumprimento das metas de déficit implicar uma transferência muito pequena para um estado? Que problemas políticos a União terá então de enfrentar? Quão crível pode ser um tal contrato no longo prazo? Problemas de reputação e credibilidade num ambiente dinâmico devem ser imperiosamente analisados antes que um mecanismo dessa natureza 
possa ser implantado. Essa análise é apresentada pelos autores como sugestão de pesquisas futuras.

\section{Referências}

Enders, W. (1995). Applied Econometric Time Series. John Wiley \& Sons, New York.

Hendry, D. F. (1995). Dynamic Econometrics. Oxford University Press, Oxford.

Issler, J. V. \& Lima, L. R. (1999). Como se equilibra o orçamento do governo no Brasil? aumento de receitas ou corte de gastos. In III Prêmio de Monografia do Tesouro Nacional. Brasília, Esaf.

Kydland, F. \& Prescott, E. (1977). Rules rather than discretion: The inconsistency of optimal plans. Journal of Political Economy, 85(3):473-90.

Oates, W. E. (1991). Federalism and government finance. Baltimore, University of Maryland (Working Paper, 40.).

Pastore, A. C. (1995). Déficit público, a sustentabilidade do crescimento das dívidas interna e externa, senhoriagem e inflação: Uma análise do regime monetário brasileiro. Revista de Econometria, 14(2):177-191.

Pires, H. A. A. (1999). Renegociação das dívidas e crise financeira dos estados. Brasília, UnB. mimeog.

Pires, H. A. A. \& Bugarin, M. S. (2001). A credibilidade da política fiscal: Um modelo de reputação para a execução das garantias fiscais pela União junto aos estados após a o programa de ajuste fiscal e a lei de responsabilidade fiscal. In Finanças Públicas. VI Prêmio Tesouro Nacional, pages 215-250. Brasília, Esaf.

Santos, G. C. (1999). A dívida dos estados: Composição, evolução e concentração. In III Prêmio de Monografia do Tesouro Nacional. Brasília, Esaf.

Svensson, L. E. O. (1997). Optimal inflation targets, "conservative" central banks, and linear inflation contracts. American Economic Review, 87(1):98-114.

Ter-Minassian, T. (1997a). Descentralização e gerenciamento macroeconômico. In Conferência Internacional Em Descentralização, Relações Fiscais Intergovernamentais e Governança Macroeconômica. Anais. Esaf/OCDE, Brasília. mimeog. 
Ter-Minassian, T. (1997b). Fiscal federalism in theory and practice. Washington, D.C., International Monetary Fund.

Trehan, B. \& Walsh, C. (1991). Testing intertemporal budget constraints: Theory and applications to U.S. federal budget and current account deficits. Journal of Money, Credit and Banking, 23(2):206-223.

Walsh, C. (1995). Optimal contracts for central bankers. American Economic Review, 85(1):150-167.

Werlang, S. R. C. \& Fraga Neto, A. (1995). Os bancos estaduais e o descontrole fiscal: Alguns aspectos. Revista Brasileira de Economia, 49(2):375-390.

Werneck, R. L. F. (1995). Federalismo fiscal e a política de estabilização no Brasil. Revista Brasileira de Economia, 49(2):375-390. 